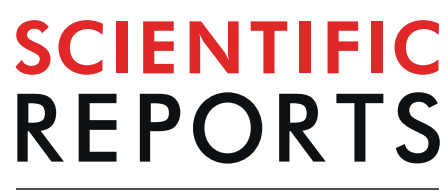

natureresearch

\title{
Prognostic value of sarcopenia in patients with colorectal liver metastases undergoing hepatic resection
}

\author{
Yueh-Wei Liu ${ }^{1}$, Chien-Chang Lu', Ching-Di Chang ${ }^{3}$, Ko-Chao Lee ${ }^{2}$, Hong Hwa Chen ${ }^{2}$, \\ Wen Shuo Yeh ${ }^{4}$, Wang-Hseng $\mathrm{Hu}^{2}$, Kai-Lung Tsai ${ }^{2}$, Cheng-Hsi Yeh ${ }^{1}$, Sin-Yong Wee ${ }^{1}$, \\ Shin-Min Yin ${ }^{1}$, Chih-Chi Wang ${ }^{1,6^{*}}$ \& Chao-Hung Hung ${ }^{4,5,6^{*}}$
}

The prognostic significance of sarcopenia has been widely studied in different cancer patients. This study aimed to analyze the influence of sarcopenia on long-term survival in patients with colorectal liver metastasis (CRLM) undergoing hepatic resection. A retrospective analysis of 182 patients undergoing hepatic resection for CRLM was performed. Sarcopenia was determinedusing the Hounsfield unit average calculation (HUAC), a measure of muscle quality-muscledensity at preoperative abdominal computed tomography scans. Sarcopenia was defined as an HUAC score of less than $22 \mathrm{HU}$ calculated using receiver operating characteristic analysis. The prognostic relevance of clinical variables and overall survival (OS) and recurrence-free survival (RFS) was evaluated. Patients with sarcopenia were older $(p<0.001)$ and had higher prevalence of diabetics $(p=0.004)$, higher body mass index (BMI) $(p<0.001)$ and neutrophil-to-lymphocyte ratio $(p=0.026)$ compared to those without. Sarcopenia was not significantly associated with OS and RFS. Multivariate Cox's regression analysis showed that multinodularity $(>3$ ) (hazard ratio (HR) 2.736; 95\% confidence interval (Cl), 1.631-4.589; $p<0.001)$, high CEA level ( $\geq 20 \mathrm{ng} / \mathrm{ml})(\mathrm{HR} 1.793 ; 95 \% \mathrm{Cl}, 1.092-2.945 ; p=0.021)$ and blood loss ( $\geq 300 \mathrm{cC}$ ) (HR1.793; 95\% Cl, $1.084-2.964 ; p=0.023$ ) were independent factors associated with OS. In subgroup analyses, sarcopenia was a significant factor of poor $O S$ in the patients with multinodularity by univariate $(p=0.002)$ and multivariate analyses(HR 3.571; 95\% Cl, 1.508-8.403; $p=0.004$ ).

Multinodularity $(>3)(\mathrm{HR} 1.750 ; 95 \% \mathrm{Cl}, 1.066-2.872 ; p=0.027)$, high aspartate aminotransferase level (HR $1.024 ; 95 \% \mathrm{Cl}, 1.003-1.046 ; p=0.025)$ and male gender ( $\mathrm{HR} 1.688 ; 95 \% \mathrm{Cl}, 1.036-2.748 ; p=0.035$ ) were independent factors of RFS. In conclusion, despite no significance in whole cohort, sarcopenia was predictive of worse OS in patients with multiple CRLM after partial hepatectomy.

Colorectal canceris one of the leading malignanciesand the fifth most frequent cause of cancer-related deathworldwide ${ }^{1,2}$. Approximately $20-25 \%$ of patients have synchronous liver metastaseswhile being diagnosed, and a further 35 to $45 \%$ of patients will develop metachronoushepatic metastases following the removal ofprimary tumor $^{3}$. The mean survival for patients with untreated colorectal liver metastasis (CRLM) has been found to range from 6-13 months ${ }^{4,5}$. Thus, the management of CRLM remains clinically challenging.

Hepatic resection is the mainstay of treatmentand potentially curative therapy for CRLM,with reported 5-year survival of $30-50 \%^{4-6}$. However, the recurrence rate has been reported to be high $(60-80 \%)$ and only $16 \%$ of these patients remain disease free for 10 years after hepatectomy ${ }^{7}$. Some studies have therefore tried to find probable

${ }^{1}$ Liver Transplant Center, Department of Surgery, Kaohsiung Chang Gung Memorial Hospital, and Chang Gung University College of Medicine, Kaohsiung, Taiwan. ${ }^{2}$ Department of Colorectal Surgery, Kaohsiung Chang Gung Memorial Hospital and Chang Gung University College of Medicine, Kaohsiung, Taiwan. ${ }^{3}$ Department of Radiology, Kaohsiung Chang Gung Memorial Hospital and Chang Gung University College of Medicine, Kaohsiung, Taiwan. ${ }^{4}$ Division of Hepatogastroenterology, Department of Internal Medicine, Kaohsiung Chang Gung Memorial Hospital and Chang Gung University College of Medicine, Kaohsiung, Taiwan. ${ }^{5}$ Division of Hepatogastroenterology, Department of Internal Medicine, Chiayi Chang Gung Memorial Hospital, Chiayi, Taiwan. ${ }^{6}$ These authors jointly supervised this work: Chih-Chi Wang and Chao-Hung Hung. *email: ufel4996@ms26.hinet.net; chh4366@yahoo.com.tw 


\begin{tabular}{|l|l|}
\hline Age (years) & $\mathbf{5 9 . 5} \pm \mathbf{1 2 . 1}$ \\
\hline Gender Male/Female & $106 / 76$ \\
\hline Body mass index $\left(\mathrm{kg} / \mathrm{m}^{2}\right)$ & $24.3 \pm 3.6$ \\
\hline Type 2 DM $(\%)$ & $40(22 \%)$ \\
\hline Synchronous(\%) & $119(65 \%)$ \\
\hline Chemotherapy & \multicolumn{2}{|l}{} \\
\hline Neoadjuvant/adjuvant/both & $35 / 166 / 28$ \\
\hline Primary tumor site* & $5 / 14 / 9 / 18 / 69 / 12 / 55$ \\
\hline C/A/T/D/S/RS/R & $3 / 22 / 73 / 84$ \\
\hline Tumor stage T1/T2/T3/T4 & $54 / 83 / 45$ \\
\hline Nodal status N0/N1/N2 & $3.9 \pm 2.5$ \\
\hline Main tumor $(\mathrm{cm})$ & $62 / 57 / 63$ \\
\hline Tumor number1/2,3/>3 & $178 \pm 880$ \\
\hline CEA (ng/ml) & $29 \pm 13$ \\
\hline AST (U/L) & $27 \pm 22$ \\
\hline ALT $(\mathrm{U} / \mathrm{L})$ & $4.1 \pm 0.4$ \\
\hline Albumin $(\mathrm{g} / \mathrm{dl})$ & $257 \pm 98$ \\
\hline Platelet $\left(10^{3} / \mu \mathrm{L}\right)$ & $2.9 \pm 2.3$ \\
\hline NLR &
\end{tabular}

Table 1. Baseline characteristics of the study cohort. ${ }^{*} \mathrm{C} / \mathrm{A} / \mathrm{T} / \mathrm{D} / \mathrm{S} / \mathrm{RS} / \mathrm{R}$ : cecum/ascending colon/transverse colon/descending colon/sigmoid colon/recto-sigmoid colon/rectum.Abbreviation: DM, diabetes mellitus; CEA, carcinoembryonic antigen; aspartate aminotransferase; ALT, alanine aminotransferase; NLR, neutrophil-tolymphocyte ratio.

\begin{tabular}{|l|l|l|l|}
\hline & $\begin{array}{l}\text { With } \\
\text { Sarcopenia }\end{array}$ & $\begin{array}{l}\text { Without } \\
\text { Sarcopenia }\end{array}$ & $\boldsymbol{p}$-value \\
\hline Case number & 48 & 134 & \\
\hline Age (years) & $66.6 \pm 10.2$ & $57.0 \pm 11.7$ & $<0.001$ \\
\hline Male (\%) & $24(50 \%)$ & $82(61 \%)$ & 0.232 \\
\hline Body mass index $\left(\mathrm{kg} / \mathrm{m}^{2}\right)$ & $25.9 \pm 4.1$ & $23.8 \pm 3.2$ & $<0.001$ \\
\hline Type 2 DM $(\%)$ & $18(38 \%)$ & $22(16 \%)$ & 0.004 \\
\hline Synchronous $(\%)$ & $27(56 \%)$ & $92(69 \%)$ & 0.157 \\
\hline Neoadjuvant chemotherapy & $10(21 \%)$ & $25(19 \%)$ & 0.831 \\
\hline Adjuvant chemotherapy & $43(90 \%)$ & $123(92 \%)$ & 0.767 \\
\hline Right-sided primary tumor $(\%)$ & $6(13 \%)$ & $22(16 \%)$ & 0.644 \\
\hline Tumor stage T3, $4 \%)$ & $41(85 \%)$ & $116(87 \%)$ & 0.811 \\
\hline Nodal status N2 (\%) & $10(21 \%)$ & $35(26 \%)$ & 0.560 \\
\hline Main tumor $(\mathrm{cm})$ & $4.1 \pm 2.3$ & $3.8 \pm 2.5$ & 0.453 \\
\hline Tumor number $>3(\%)$ & $14(29 \%)$ & $49(37 \%)$ & 0.382 \\
\hline CEA (ng/ml) & $356 \pm 1412$ & $114 \pm 571$ & 0.102 \\
\hline AST (U/L) & $28 \pm 14$ & $29 \pm 13$ & 0.575 \\
\hline ALT (U/L) & $22 \pm 12$ & $29 \pm 23$ & 0.153 \\
\hline Albumin $(g / d l)$ & $3.9 \pm 0.8$ & $4.1 \pm 0.5$ & 0.072 \\
\hline Platelet $\left(10^{3} / \mu \mathrm{L}\right)$ & $305 \pm 124$ & $295 \pm 102$ & 0.601 \\
\hline NLR & $3.5 \pm 3.4$ & $2.7 \pm 1.7$ & 0.026 \\
\hline
\end{tabular}

Table 2. Comparison of demographic and clinical characteristics of patients with and without sarcopenia. Data are expressed as mean \pm standard deviation or number (percentage). Abbreviation: DM, diabetes mellitus; CEA, carcinoembryonic antigen; aspartate aminotransferase; ALT, alanine aminotransferase; NLR, neutrophil-tolymphocyte ratio.

prognostic predictors affecting CRLM receiving resection, including elder age, number and size of hepatic lesions, the primary lymph node status and preoperative anemia ${ }^{8,9}$. This issue should be further clarified with the advances of new chemotherapeutic regimensand target therapy as well as the operative technique.

Sarcopenia is a syndrome characterized by loss of muscle mass, function and strength that is quantifiable using cross sectional imaging by measurement of psoas area and the muscle's density ${ }^{10,11}$. Recently, there is increasing evidence that sarcopeniais an important prognostic factor of frailty, mortality, and worse surgical outcomes ${ }^{12}$. Sarcopenia has been reported to affect not only operative complications ${ }^{13}$, but also cancer-specific outcomes following hepatic resection ${ }^{14,15}$, colectomy ${ }^{16}$, and pancreatic resection ${ }^{17}$. Until now, the role of sarcopenia in the 


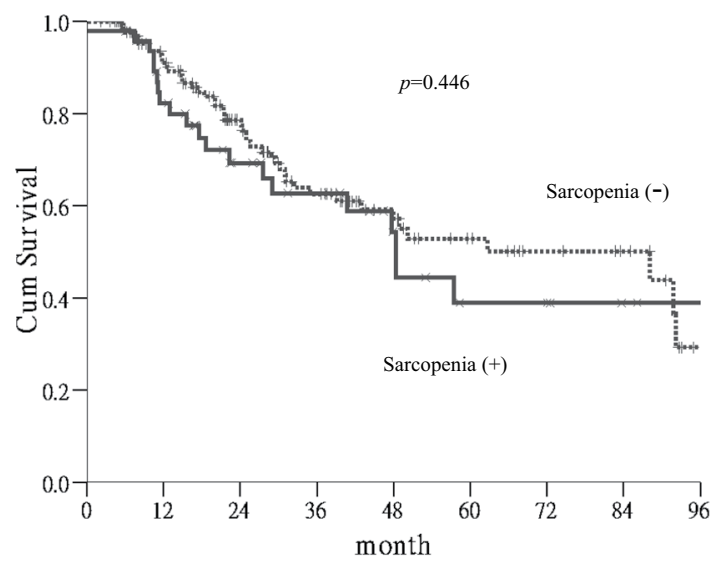

No. at risk

$\begin{array}{lllllllll}\text { Sarcopenia }(+) & 48 & 36 & 23 & 18 & 11 & 6 & 6 & 3\end{array}$

$\begin{array}{lllllllll}\text { Sarcopenia (-) } & 134 & 107 & 69 & 46 & 29 & 20 & 14 & 12\end{array}$

Figure 1. Kaplan-Meier curves for overall survival. Significance was not found between patients with and without sarcopenia $(p=0.446)$.

long-term survival of patients with CRLMafter partial hepatectomy remains limited ${ }^{15,18}$. Thus, we conducted this study to clarify this issue.

\section{Materials and methods}

Study population. Between July 2008 and July 2018, 193 consecutive patients who underwent curative intent surgery for CRLM were identified from a single tertiary center. Of them, 11 patients without available abdominal computed tomography (CT) images within 30 days of surgerywere excluded. Preoperative workup included triple phase-contrast enhanced CT scan, in which liver volume assessment was performed when indicated. Magnetic resonance imaging (MRI) and/or positron emission tomography (PET) scan were arranged to confirm doubtful cases. These cases were discussed in a multidisciplinary meeting to decide combined or delayed surgery with or without pre-operativechemotherapy. Written informed consent was obtained from all participants. This study was approved by the Research Ethics Committee of Chang Gung Memorial Hospital (IRB No. 201900541B0) and was conducted in accordance with the principles of Declaration of Helsinki and the International Conference on Harmonization for Good Clinical Practice.

Image analysis. Preoperative abdominal CT scans were performed on a GE Discovery CT750 HD lightspeed scanner. Evaluation for sarcopenia was performed using CT measures ofmuscle quality-muscledensity (measured in Hounsfield units (HU))as previously described ${ }^{19-21}$. All measurements and segmentations were done at the level of the inferior endplate of L4 on axial CT images. To measure muscle density, the paraspinal muscles were outlined using a freehand region-of-interest (ROI) tool on a General Electric Picture Archiving and Communicating System (S1000). The total cross-sectional area of bilateral paraspinal, psoas, and abdominal wall muscles at L4 were evaluated on OsiriX imaging software v. 8.0.2 (Pixmeo, Geneva, Switzerland) with the lean muscle threshold set at -29 to $150 \mathrm{HU}^{19-21}$. The final Hounsfield unit average calculation (HUAC)was the average ofleft $\mathrm{HU}$ and right $\mathrm{HU}$ to determine the presence or absence of sarcopenia in the study population.

Follow-up. The regimens of chemotherapy included fluorouracil and leucovorin, combined with irinotecan and/or oxaliplantin, which was currently the standard treatment for CRLM. Follow-up consisted of out patient visits with serum carcinoembryonic antigen (CEA) levels and imagesevery 3 to 6 months after surgery. Overall survival (OS) was defined as the time interval from the date of hepatic resectionto death from any cause or the last follow-up date. Recurrence-free survival (RFS) was defined as the period after hepatic resection to the date when recurrent tumors were diagnosed.

Statistical analysis. Continuous data were presented as mean \pm standard deviation and compared by using Student's $t$ test. Categorical variables were expressed as number (percentage) and analyzed by using the $\chi^{2}$ or Fisher's exact test depending on the size of the sample. A receiver-operating characteristic (ROC) curve was used to determine the best cutoff of HUAC scorebased on the Youden index. Kaplan-Meier curves were generated for OS and RFS and the differences of survival rates between groups were compared using the log-rank test. The Cox proportional hazards model was employed for univariate and multivariate analyses. The analysis software used was SPSS for Windows version 18 (SPSS Inc., Chicago, IL, USA). All statistical tests were two-sided and differences were considered significant with a $p<0.05$. 


\begin{tabular}{|c|c|c|c|c|c|}
\hline & \multirow[b]{2}{*}{ Comparison } & \multicolumn{2}{|l|}{ Univariate analyses } & \multicolumn{2}{|c|}{ Stepwise multivariate analyses } \\
\hline & & HR $(95 \% \mathrm{CI})$ & $p$-value & HR (95\% CI) & $p$-value \\
\hline Age (years) & $\geq 60$ vs. $<60$ & $0.785(0.483-1.276)$ & 0.328 & & \\
\hline Gender & Male vs. Female & $1.132(0.694-1.849)$ & 0.619 & & \\
\hline $\operatorname{BMI}\left(\mathrm{kg} / \mathrm{m}^{2}\right)$ & $\geq 25$ vs. $<25$ & $0.683(0.410-1.135)$ & 0.141 & & \\
\hline $\mathrm{DM}$ & Yes vs. No & $1.365(0.785-2.374)$ & 0.270 & & \\
\hline Sarcopenia & Yes vs. No & $1.226(0.725-2.073)$ & 0.447 & & \\
\hline Synchronous & Yes vs. No & $0.911(0.545-1.522)$ & 0.722 & & \\
\hline Neoadjuvant chemotherapy & Yes vs. No & $1.116(0.596-2.092)$ & 0.731 & & \\
\hline Adjuvant chemotherapy & Yes vs. No & $1.303(0.522-3.250)$ & 0.571 & & \\
\hline Blood loss (cc) & $\geq 300$ vs. $<300$ & $2.116(1.293-3.461)$ & 0.003 & $1.793(1.084-2.964)$ & 0.023 \\
\hline CEA (ng/ml) & $\geq 20$ vs. $<20$ & $1.639(1.008-2.663)$ & 0.046 & $1.793(1.092-2.945)$ & 0.021 \\
\hline Primary tumor site & right vs. left & $1.530(0.775-3.021)$ & 0.220 & & \\
\hline Tumor stage & T3,4 vs. 2 & $1.305(0.622-2.735)$ & 0.481 & & \\
\hline Nodal status & N2 vs. N0, 1 & $1.639(0.981-2.739)$ & 0.059 & & \\
\hline Main tumor $(\mathrm{cm})$ & $>3$ vs. $\leq 3$ & $1.783(1.085-2.930)$ & 0.023 & & \\
\hline Tumor number & $>3$ vs. $\leq 3$ & $2.733(1.675-4.459)$ & $<0.001$ & $2.736(1.631-4.589)$ & $<0.001$ \\
\hline AST (U/L) & per $1 \mathrm{U} / \mathrm{L}$ increase & $1.016(0.999-1.032)$ & 0.068 & & \\
\hline $\operatorname{ALT}(\mathrm{U} / \mathrm{L})$ & per $1 \mathrm{U} / \mathrm{L}$ increase & $1.007(0.992-1.022)$ & 0.361 & & \\
\hline Albumin $(\mathrm{g} / \mathrm{dl})$ & per $1 \mathrm{~g} / \mathrm{dl}$ increase & $0.744(0.533-1.038)$ & 0.082 & & \\
\hline Platelet $\left(10^{3} / \mu \mathrm{L}\right)$ & per $10^{3} / \mu \mathrm{L}$ increase & $1.003(1.001-1.005)$ & 0.016 & & \\
\hline NLR & $>3$ vs. $\leq 3$ & $1.055(0.608-1.830)$ & 0.849 & & \\
\hline
\end{tabular}

Table 3. Univariate and stepwise multivariate analyses of factors associated with overall survival. Abbreviation: HR, hazard ratio; CI, confidence interval; DM, diabetes mellitus; CEA, carcinoembryonic antigen; aspartate aminotransferase; ALT, alanine aminotransferase; NLR, neutrophil-to-lymphocyte ratio.

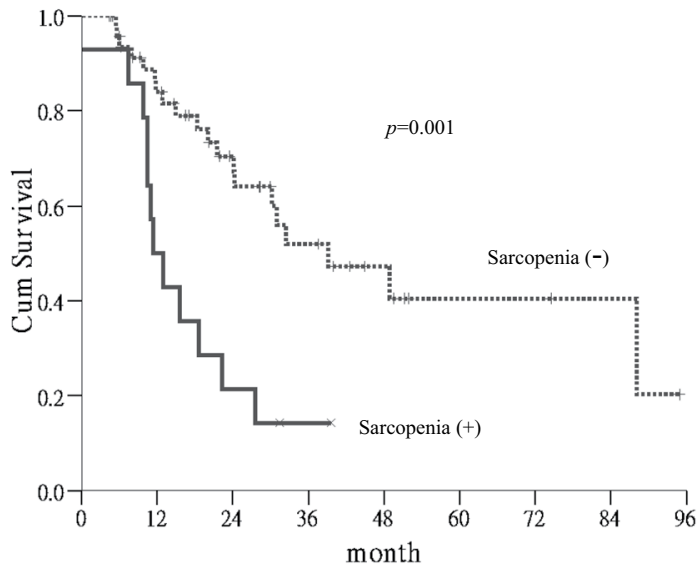

No. at risk

$\begin{array}{llllllllll}\text { Sarcopenia }(+) & 14 & 7 & 3 & 1 & 0 & 0 & 0 & 0\end{array}$

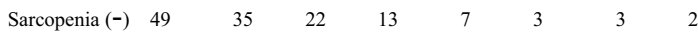

Figure 2. Kaplan-Meier curves for overall survival in subgroup patients. Sarcopenia was a significant factor of poor OS in the patients withmultinodularity $(p=0.001)$.

\section{Results}

Patient characteristics. Among the study population, the mean age was $59.5 \pm 12.1$ years with a range 21-85 years, and 106 of them were male. Sixty-twopatients had solitary tumor whereas 57 had 2-3 tumors, and 63 had more than 3 tumors. Neoadjuvant chemotherapy was given in 35 of 182 patients (19.2\%), and 166(91.2\%) patients received adjuvant chemotherapy after hepatic resection (Table 1).

ROC analysis for HUAC score in the survival status at the 5-year follow-up identified an optimal cutoffat HUAC of 22 HU. At this cutoff, 48 (26.4\%) patients were considered sarcopenic. Patients with sarcopenia were older $(p<0.001)$ and had higher prevalence of diabetics $(p=0.004)$, higher body mass index (BMI) $(p<0.001)$ 


\begin{tabular}{|c|c|c|c|c|c|}
\hline & \multirow[b]{2}{*}{ Comparison } & \multicolumn{2}{|l|}{ Univariate analyses } & \multicolumn{2}{|c|}{ Stepwise multivariate analyses } \\
\hline & & HR $(95 \% \mathrm{CI})$ & $p$-value & HR $(95 \% \mathrm{CI})$ & $p$-value \\
\hline Age (years) & $\geq 60$ vs. $<60$ & $0.592(0.291-1.202)$ & 0.147 & & \\
\hline Gender & Male vs. Female & $1.151(0.563-2.352)$ & 0.701 & & \\
\hline $\mathrm{BMI}\left(\mathrm{kg} / \mathrm{m}^{2}\right)$ & $\geq 25$ vs. $<25$ & $1.373(0.672-2.806)$ & 0.384 & & \\
\hline $\mathrm{DM}$ & Yes vs. No & $1.078(0.515-2.258)$ & 0.842 & & \\
\hline Sarcopenia & Yes vs. No & $3.322(1.585-6.993)$ & 0.002 & $3.571(1.508-8.403)$ & 0.004 \\
\hline Synchronous & Yes vs. No & $1.866(0.755-4.610)$ & 0.177 & & \\
\hline Neoadjuvant chemotherapy & Yes vs. No & $1.226(0.589-2.551)$ & 0.585 & & \\
\hline Adjuvant chemotherapy & Yes vs. No & $0.298(0.088-1.008)$ & 0.051 & & \\
\hline Blood loss (cc) & $\geq 300$ vs. $<300$ & $1.940(0.956-3.936)$ & 0.067 & & \\
\hline CEA (ng/ml) & $\geq 10$ vs. $<10$ & $1.627(0.808-3.273)$ & 0.173 & & \\
\hline Primary tumor site & right vs. left & $1.699(0.645-4.475)$ & 0.283 & & \\
\hline Tumor stage & T3,4 vs. 2,1 & $1.147(0.348-3.787)$ & 0.821 & & \\
\hline Nodal status & N2 vs. N0, 1 & $1.124(0.536-2.353)$ & 0.757 & & \\
\hline Main tumor $(\mathrm{cm})$ & $>3$ vs. $\leq 3$ & $1.822(0.865-3.836)$ & 0.114 & & \\
\hline $\operatorname{AST}(\mathrm{U} / \mathrm{L})$ & per $1 \mathrm{U} / \mathrm{L}$ increase & $1.000(0.979-1.021)$ & 0.966 & & \\
\hline $\operatorname{ALT}(\mathrm{U} / \mathrm{L})$ & per $1 \mathrm{U} / \mathrm{L}$ increase & $0.998(0.982-1.014)$ & 0.776 & & \\
\hline Albumin (g/dl) & per $1 \mathrm{~g} / \mathrm{dl}$ increase & $0.356(0.115-1.098)$ & 0.072 & & \\
\hline Platelet $\left(10^{3} / \mu \mathrm{L}\right)$ & per $10^{3} / \mu$ L increase & $1.002(0.997-1.008)$ & 0.353 & & \\
\hline NLR & $>3$ vs. $\leq 3$ & $1.234(0.563-2.703)$ & 0.599 & & \\
\hline
\end{tabular}

Table 4. Factors associated with overall survival in subgroup patients with multiple CRLM. Abbreviation: CRLM, colorectal liver metastasis; HR, hazard ratio; CI, confidence interval; DM, diabetes mellitus; CEA, carcinoembryonic antigen; aspartate aminotransferase; ALT, alanine aminotransferase; NLR, neutrophil-tolymphocyte ratio.

and neutrophil-to-lymphocyte ratio $(p=0.026)$ compared to those without sarcopenia (Table 2$)$. Themajor complications were equally common in sarcopenic and non-sarcopenic patients.

Factors associated with OS. The mean follow-up was $32.5 \pm 25.5$ months (range 2-121). The 1-, 3-, and 5 -year OS rates of patients were $89 \%, 63 \%$, and $49 \%$, respectively. Sarcopenia was not a prognostic factor for OS, as the mean OS durations for patients with sarcopenia was $32.3 \pm 25.0$ months vs. $33.0 \pm 27.1$ months for those without sarcopenia (Fig. 1).

Univariate analyses showed significant associations of unfavourable OS were multinodularity $(>3)(p<0.001)$, main tumor size $(\geq 3 \mathrm{~cm})(p=0.023)$, blood loss $(\geq 300 \mathrm{cc})(p=0.003)$, CEA level $(\geq 20 \mathrm{ng} / \mathrm{ml})(p=0.046)$ and platelet count $(p=0.016)$. By multivariate Cox proportional hazards model of factors with $\mathrm{p}<0.2$ in univariate analyses, multinodularity (hazard ratio (HR) 2.736; 95\% confidence interval (CI), 1.631-4.589; $p<0.001$ ), high CEA level $(\geq 20 \mathrm{ng} / \mathrm{ml})(\mathrm{HR} 1.793 ; 95 \%$ CI, 1.092-2.945; $p=0.021)$ and blood loss $(\geq 300 \mathrm{cc})$ (HR 1.793; 95\% CI, 1.084-2.964; $p=0.023$ ) were independent factors for OS (Table 3).

In subgroup analyses, sarcopenia was a significant factor of poor OS in the patients with multinodularity $(p=0.001)$ (Fig. 2). In contrast, there were no associations of sarcopenia with OS in other subgroup analyses, such as age, gender, diabetes, tumor size, etc. Table 4 shows thefactors associated with OS in subgroup patients with multiple CRLM. Sarcopenia was the significant factor associated with poor OS in the patients with multiple CRLM by univariate $(p=0.002)$ and multivariate analyses(HR 3.571; 95\% CI, 1.508-8.403; $p=0.004)$.

Factors associated with RFS. The 1-, 3-, and 5-year RFS rates of patients were 59\%, 33\%, and 25\%, respectively. Sarcopenia was not a significant factor for RFS (Fig. 3). As shown in Table 5, multinodularity $(p<0.001)$, main tumor size $(\geq 3 \mathrm{~cm})(p=0.017)$, male gender $(p=0.035)$ and higher pretreatment serum levels of aspartate aminotransferase (AST) $(p=0.004)$ and alanine aminotransferase (ALT) $(p=0.008)$ were associated with shorter RFS. Multivariate Cox's regression analyses showed that multinodularity ( $>3$ ) (HR 1.750; 95\% CI, 1.066-2.872; $p=0.027$ ), high AST level (HR 1.024; 95\% CI, 1.003-1.046; $p=0.025)$ and male gender (HR 1.688; 95\% CI, $1.036-2.748 ; p=0.035$ ) were independent factors (Table 5).

\section{Discussion}

This present study showed that preoperative sarcopenia was not associated with long-term survival in a homogeneous population of CRLM undergoing hepatic resection. Sarcopeniawas not a significant risk factor of OS and RFS in our study population. However, our study provided the first evidence that sarcopenia predicted worse OS in the subgroup patients with multinodularity $(>3)$.

A number of clinicopathological factors have been constantly reported as having prognostic value following hepatectomy of CRLM ${ }^{8,9,22-24}$. In this study, we demonstrated that multinodularity ( $\left.>3\right)$, high CEA level $(\geq 20 \mathrm{ng} /$ $\mathrm{ml}$ ) and blood loss $(>300 \mathrm{cc}$ ) were independent factors associated with poorer OS. Our data were compatible with those reported in most studies ${ }^{8,9,22-24}$, showing that the number of liver metastaseswas the most important negative predictor not only for OS but also for RFS. In contrast, the location of primary tumoremerging as an 


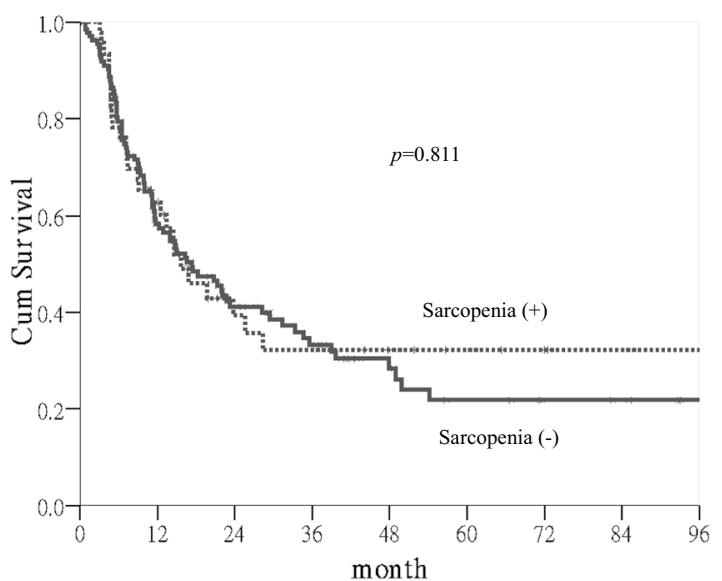

No. at risk

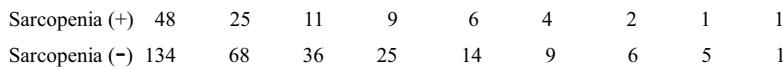

Figure 3. Kaplan-Meier curves for recurrence-free survival. Significance was not found between patients with and without sarcopenia $(\mathrm{p}=0.811)$.

\begin{tabular}{|c|c|c|c|c|c|}
\hline & \multirow[b]{2}{*}{ Comparison } & \multicolumn{2}{|l|}{ Univariate analyses } & \multicolumn{2}{|l|}{$\begin{array}{l}\text { Stepwise multivariate } \\
\text { analyses }\end{array}$} \\
\hline & & HR (95\% CI) & $p$-value & HR $(95 \% \mathrm{CI})$ & $p$-value \\
\hline Age (years) & $\geq 60$ vs. $<60$ & $0.897(0.617-1.305)$ & 0.571 & & \\
\hline Gender & Male vs. Female & $1.519(1.030-2.239)$ & 0.035 & $1.688(1.036-2.748)$ & 0.035 \\
\hline BMI $(\mathrm{kg} / \mathrm{m} 2)$ & $\geq 25$ vs. $<25$ & $0.937(0.637-1.377)$ & 0.739 & & \\
\hline $\mathrm{DM}$ & Yes vs. No & $1.073(0.681-1.689)$ & 0.762 & & \\
\hline Sarcopenia & Yes vs. No & $1.054(0.683-1.628)$ & 0.811 & & \\
\hline Synchronous & Yes vs. No & $1.129(0.760-1.678)$ & 0.548 & & \\
\hline Neoadjuvant chemotherapy & Yes vs. No & $0.854(0.521-1.401)$ & 0.533 & & \\
\hline Adjuvant chemotherapy & Yes vs. No & $1.814(0.839-3.919)$ & 0.130 & & \\
\hline Blood loss (cc) & $\geq 300$ vs. $<300$ & $1.451(0.987-2.134)$ & 0.058 & & \\
\hline CEA (ng/ml) & $\geq 20$ vs. $<20$ & $1.374(0.931-2.029)$ & 0.110 & & \\
\hline Primary tumor site & right vs. left & $0.704(0.394-1.260)$ & 0.238 & & \\
\hline Tumor stage & T3,4 vs. 2,1 & $1.538(0.844-2.803)$ & 0.160 & & \\
\hline Nodal status & N2 vs. N0, 1 & $1.259(0.827-1.918)$ & 0.283 & & \\
\hline Main tumor $(\mathrm{cm})$ & $>3$ vs. $\leq 3$ & $1.588(1.086-2.322)$ & 0.017 & & \\
\hline Tumor number & $>3$ vs. $\leq 3$ & $2.222(1.505-3.281)$ & $<0.001$ & $1.750(1.066-2.872)$ & 0.027 \\
\hline $\operatorname{AST}(\mathrm{U} / \mathrm{L})$ & per $1 \mathrm{U} / \mathrm{L}$ increase & $1.021(1.006-1.035)$ & 0.004 & $1.024(1.003-1.046)$ & 0.025 \\
\hline $\operatorname{ALT}(\mathrm{U} / \mathrm{L})$ & per $1 \mathrm{U} / \mathrm{L}$ increase & $1.016(1.004-1.027)$ & 0.008 & & \\
\hline Albumin (g/dl) & per $1 \mathrm{~g} / \mathrm{dl}$ increase & $1.025(0.738-1.423)$ & 0.883 & & \\
\hline Platelet $\left(10^{3} / \mu \mathrm{L}\right)$ & per $10^{3} / \mu \mathrm{L}$ increase & $0.999(0.998-1.001)$ & 0.594 & & \\
\hline NLR & $>3$ vs. $\leq 3$ & $0.984(0.651-1.488)$ & 0.939 & & \\
\hline
\end{tabular}

Table 5. Univariate and stepwise multivariate analyses of factors associated with recurrence -free survival. Abbreviation: HR, hazard ratio; CI, confidence interval; DM, diabetes mellitus; CEA, carcinoembryonic antigen. aspartate aminotransferase; ALT, alanine aminotransferase; NLR, neutrophil-to-lymphocyte ratio.

important prognostic factor was not significant in our study ${ }^{25}$. This could be attributed to the small case number of right sided cancer in this series.

Recently, the use of sarcopenia to predict outcomes in cancer patients has attracted more attention, including those with CRLM undergoing hepatic resection. Previous studies demonstrated that sarcopenia increased risk of post-operative morbidity and longer hospital stay as well as readmission ratesafter partial liver resection for $\mathrm{CRLM}^{15,18}$. On the contrary, sarcopeniadid not seemto impact long-term outcomes in their patients. Our data, in line with their results, showed that sarcopenia was not a significant risk factor of OS and RFS. Moreover, considering the greater impact of other stronger risk factors such as tumor number, we therefore analyzed the effect of 
sarcopenia on the subgroups of our patients. Interestingly, we found that sarcopenia was significantly predictive of worse OS in the patients with multiple CRLM. Based on our findings, we recommended that patients with multiple (>3) CRLM and combined sarcopenia, hepatic resection might be considered cautiously due to limited survival. However, further studies with longer follow-up periods should be necessary to confirm our observation.

In our study population, sarcopenia was associated with advanced age, diabeticsand obesity. Although these results were discrepant with other findings ${ }^{15,26}$, our data were consistent with a recent report showing that age and obesity were found to be independently associated with sarcopenia in patients undergoing liver transplant evaluation $^{27}$. Previous studies have reported that patients with sarcopenic obesity had worse survival in hepatocellular carcinoma receiving hepatectomy or after living donor liver transplantation ${ }^{28-31}$. While our data in accordance with a recent study showed that sarcopenicobesity was not a prognostic factor in patientsundergoingliver resection for CRLM ${ }^{32}$.

This present study is limited based on its retrospective nature and thus there may have been selection bias. Moreover, we believed that the bias was smallbecause patientswere followed regularly with clinical and laboratory assessment using CEA and imaging studies every 3 to 6 months. Secondly, we defined obesity as BMI $\geqq 25 \mathrm{~kg} /$ $\mathrm{m}^{2}$ by clinical diagnosis, whereas other studies assessed the visceral adipose tissueusing CT evaluation ${ }^{18,29}$. However, a previous study has showna close positive correlation of BMI with visceral adipose tissue, andobesity is adequately specified as a $\mathrm{BMI} \geqq 25 \mathrm{~kg} / \mathrm{m}^{2}$ in Asian populations ${ }^{33}$. Third, the recent novel mutational molecular markers, such as microsatellite instability, BRAF, and KRAS/NRAS and combination mutations which conferred poorer outcomeswere not available in our study ${ }^{24}$. It willbe interesting to determine the association of molecular markerswith long-term prognosisin patients with CRLM after partial hepatectomy in further studies.

In conclusion, in spite of no significance in long-term outcomes in whole cohort, sarcopenia is associated with an increased survival risk of patients with multiple CRLM undergoing hepatic resection. Assessment of preoperative sarcopenia provides an easy tool for selection of CRLM patients for liver resection. Further large-scale and multicenter studies are stillneeded to clarify these issues.

Received: 21 October 2019; Accepted: 3 April 2020;

Published online: 15 April 2020

\section{References}

1. Jones, R. P. et al. Colorectal Liver Metastases: A Critical Review of State of the Art. Liver Cancer. 6, 66-71 (2016).

2. Jenkins, L. T., Millikan, K. W., Bines, S. D., Staren, E. D. \& Doolas, A. Hepatic resection for metastatic colorectal cancer. Am Surg. 63, 605-610 (1997).

3. Howard, C. et al. Synchronous colorectal liver metastases: a national survey of surgeon opinions on simultaneous resection and multidisciplinary cooperation. Hepatobiliary Surg Nutr. 7, 242-250 (2018).

4. Abdalla, E. K. et al. Recurrence and outcomes following hepatic resection, radiofrequency ablation, and combined resection/ ablation for colorectal liver metastases. Ann Surg. 239, 825-827 (2004).

5. Kornprat, P. et al. Outcome after hepatectomy for multiple (four or more) colorectal metastases in the era of effective chemotherapy. Ann Surg Oncol. 14, 1151-1160 (2007).

6. Vigano, L. et al. Progression of colorectal liver metastases from the end of chemotherapy to resection: a new contraindication to surgery? Ann Surg Oncol. 25, 1676-1685 (2018).

7. Tomlinson, J. S. et al. Actual 10-year survival after resection of colorectal liver metastases defines cure. J Clin Oncol. 25, 4575-4580 (2007).

8. Creasy, J. M. et al. Actual 10-year survival after hepatic resection of colorectal liver metastases: What factors preclude cure? Surgery. 163, 1238-1244 (2018).

9. Kulik, U. et al. Liver resection of colorectal liver metastases in elderly patients. World J Surg. 35, 2063-2072 (2011).

10. Kim, T. N. \& Choi, K. M. Sarcopenia: Definition, epidemiology, and pathophysiology. J Bone Metab. 20, 1-10 (2013).

11. Damuth, E., Mitchell, J. A., Bartock, J. L., Roberts, B. W. \& Trzeciak, S. Long-term survival of critically ill patients treated with prolonged mechanical ventilation: a systematic review and meta-analysis. Lancet Respir Med. 3, 544-553 (2015).

12. Friedman, J., Lussiez, A., Sullivan, J., Wang, S. \& Englesbe, M. Implications of sarcopenia in major surgery. Nutr Clin Pract. 30, 175-179 (2015).

13. Englesbe, M. J. et al. Sarcopenia and mortality after liver transplantation. J Am Coll Surg. 211, 271-278 (2010).

14. Itoh, S. et al. Effect of body composition on outcomes after hepatic resection for hepatocellular carcinoma. Ann Surg Oncol. 21, 3063-3068 (2014).

15. Peng, P. D. et al. Sarcopenia negatively impacts short- term outcomes in patients undergoing hepatic resection for colorectal liver metastasis. HPB (Oxford). 13, 439-446 (2011).

16. Reisinger, K. W. et al. Functional compromise reflected by sarcopenia, frailty, and nutritional depletion predicts adverse postoperative outcome after colorectal cancer surgery. Ann Surg. 261, 345-352 (2015).

17. Peng, P. et al. Impact of sarcopenia on outcomes following resection of pancreatic adenocarcinoma. J Gastrointest Surg. 16, 1478-1486 (2012).

18. Lodewick, T. M. et al. Are sarcopenia, obesity and sarcopenic obesity predictive of outcome in patients with colorectal liver metastases? HPB (Oxford). 17, 438-446 (2015).

19. Englesbe, M. J. et al. Analytic morphomics, core muscle size, and surgical outcomes. Ann Surg. 256, 255-261 (2012).

20. Chang, C. D. et al. Effect of sarcopenia on clinical and surgical outcome in elderly patients with proximal femur fractures. Skeletal Radiol. 47, 771-777 (2018).

21. Boutin, R. D., Yao, L., Canter, R. J. \& Lenchik, L. Sarcopenia: current concepts and imaging implications. Am J Roentgenol. 205, W255-66 (2015).

22. Fong, Y., Fortner, J., Sun, R. L., Brennan, M. F. \& Blumgart, L. H. Clinical score for predicting recurrence after hepatic resection for metastatic colorectal cancer: analysis of 1001 consecutive cases. Ann Surg. 230, 309-318 (1999).

23. Fuks, D. et al. Colorectal carcinoma with potentially resectable metastases: factors associated with the failure of curative schedule. Gastroenterol Clin Biol. 32, 390-400 (2008).

24. Rehman, A. H., Jones, R. P. \& Poston, G. Prognostic and predictive markers in liver limited stage IV colorectal cancer. Eur J Surg Oncol. 45, 2251-2256 (2019).

25. Wang, X. Y. et al. Meta-analysis of the association between primary tumour location and prognosis after surgical resection of colorectal liver metastases. Br J Surg. 106, 1747-1760 (2019).

26. Park, Y. S. et al. Sarcopenia is associated with an increased risk of advanced colorectal neoplasia. Int J Colorectal Dis. 32, 557-565 (2017). 
27. Carias, S. et al. Nonalcoholic steatohepatitis is strongly associated with sarcopenic obesity in patients with cirrhosis undergoing liver transplant evaluation. J Gastroenterol Hepatol. 31, 628-633 (2016).

28. Itoh, S. et al. Effect of Sarcopenic Obesity on Outcomes of Living-Donor Liver Transplantation for Hepatocellular Carcinoma. Anticancer Res. 36, 3029-3034 (2016).

29. Kobayashi, A. et al. Impact of Sarcopenic Obesity on Outcomes in Patients Undergoing Hepatectomy for Hepatocellular Carcinoma. Ann Surg. 269, 924-931 (2019).

30. Kamo, N. et al. Impact of sarcopenic obesity on outcomes in patients undergoing living donor liver transplantation. Clin Nutr. 38, 2202-2209 (2019).

31. Hamaguchi, Y. et al. Preoperative Visceral Adiposity and Muscularity Predict Poor Outcomes after Hepatectomy for Hepatocellular Carcinoma. Liver Cancer. 8, 92-109 (2019).

32. Kobayashi, A. et al. Impact of Visceral Adiposity as Well as Sarcopenic Factors on Outcomes in Patients Undergoing Liver Resection for Colorectal Liver Metastases. World J Surg. 42, 1180-1191 (2018).

33. Examination Committee of Criteria for 'Obesity Disease' in Japan. Japan Society for the Study of Obesity. New criteria for "obesity disease" in Japan. Circ J. 66, 987-992 (2002).

\section{Author contributions}

Conception and design: Y.W. Liu, C.H. Hung. Analysis and interpretation of data: Y.W. Liu, C.H. Hung. Drafting of the article: Y.W. Liu, C.H. Hung. Critical revision of the article for important intellectual content: Y.W. Liu, C.C. Lu, C.D. Chang, K.C. Lee, H.H. Chen, W.S. Yeh, W.H. Hu, K.L. Tsai, C.H. Yeh, S.Y. Wee, S.M. Yin, C.C. Wang, C.H. Hung. Final approval of the article: Y.W. Liu, C.C. Lu, C.D. Chang, K.C. Lee, H.H. Chen, W.S. Yeh, W.H. Hu, K.L. Tsai, C.H. Yeh, S.Y. Wee, S.M. Yin, C.C. Wang, C.H. Hung. Provision of study materials or patients: Y.W. Liu, C.C. Lu, K.C. Lee, H.H. Chen, W.S. Yeh, W.H. Hu, K.L. Tsai, C.H. Yeh, S.Y. Wee, S.M. Yin, C.C. Wang. Statistical expertise: C.H. Hung. Collection and assembly of data: C.H. Hung.

\section{Competing interests}

The authors declare no competing interests.

\section{Additional information}

Correspondence and requests for materials should be addressed to C.-H.H.

Reprints and permissions information is available at www.nature.com/reprints.

Publisher's note Springer Nature remains neutral with regard to jurisdictional claims in published maps and institutional affiliations.

(c) (i) Open Access This article is licensed under a Creative Commons Attribution 4.0 International License, which permits use, sharing, adaptation, distribution and reproduction in any medium or format, as long as you give appropriate credit to the original author(s) and the source, provide a link to the Creative Commons license, and indicate if changes were made. The images or other third party material in this article are included in the article's Creative Commons license, unless indicated otherwise in a credit line to the material. If material is not included in the article's Creative Commons license and your intended use is not permitted by statutory regulation or exceeds the permitted use, you will need to obtain permission directly from the copyright holder. To view a copy of this license, visit http://creativecommons.org/licenses/by/4.0/.

(C) The Author(s) 2020 